\title{
Numerical Simulation of Welding Dissimilar Steel Sheets for Use in Tailor-Welded Blanks
}

\author{
Islam El-Galy, Ahmed R. Elmasry, Ali El-Ashram
}

\begin{abstract}
Tailor-welded blanks (TWBs) are primarily used in the automotive industry. Popular applications include: side frames, doors, pillars and rails. The TWB concept has several disadvantages. The most important disadvantage is the effect of the weld line on the formability of the TWB. This paper investigates the weldment quality by evaluating the localized stresses, strains and distortions that develop during welding. For the purpose of investigation, TWBs made of 304 stainless steel and A619 low carbon steel have been numerically simulated using a finite volume formulation. Blanks with different configurations (blank sizes, thicknesses and weldment type) have been simulated, so that the optimal processing parameters for each configuration can be determined. Conclusion about the scaling effect and the residual stresses in the welded blanks could be drawn based upon the evaluation of the different configurations.
\end{abstract}

Keywords - TWB, Scaling effect, Numerical simulation, Finite volume, GMAW, Dissimilar materials, Failure prediction

\section{Introduction}

The concept of Tailor Welded Blanks (TWBs) is to build the substructure by welding the flat blanks required to form its main subcomponents first and then forming the welded blank [1]. Thus, only one forming operation is required to fabricate the substructure [2]. Figure 1 shows different joint configurations for TWBs. TWBs consist of different types of sheet stock with similar or different thicknesses, grades/strengths, and sometimes coatings. When different materials or variable thickness blanks are produced, it is possible to make finished parts with a desirable variation in properties such as strength, corrosion resistance, and so on [3].

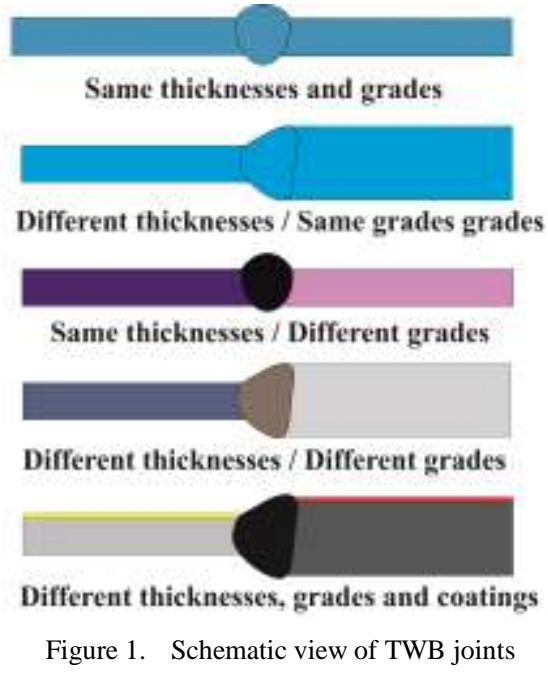

Islam El-Galy*, Ahmed R. Elmasry, Ali El-Ashram

Department of Production Engineering,

Faculty of Engineering, Alexandria University, Egypt
TWB process was first developed as a method for utilizing collectible offal and improving blank nesting possibilities. Currently, its greatest potential lies in the area of blanks with different thicknesses, coatings, and material grades. TWBs give the product designer the opportunity to eliminate reinforcements while improving structural and dimensional characteristics. The main benefit is weight reduction, which is derived from optimization of material and gage reductions in specified areas. In addition, the TWB process allows for part integration, eliminating the need for reinforcements and stiffeners [3]. In the automotive industry, tailor-welded blanks are used to provide optimum strength using the least amount of material possible for specific points on a vehicle [2]. In Figure 2, a schematic representation of current and/or potential TWB body components is represented [4].

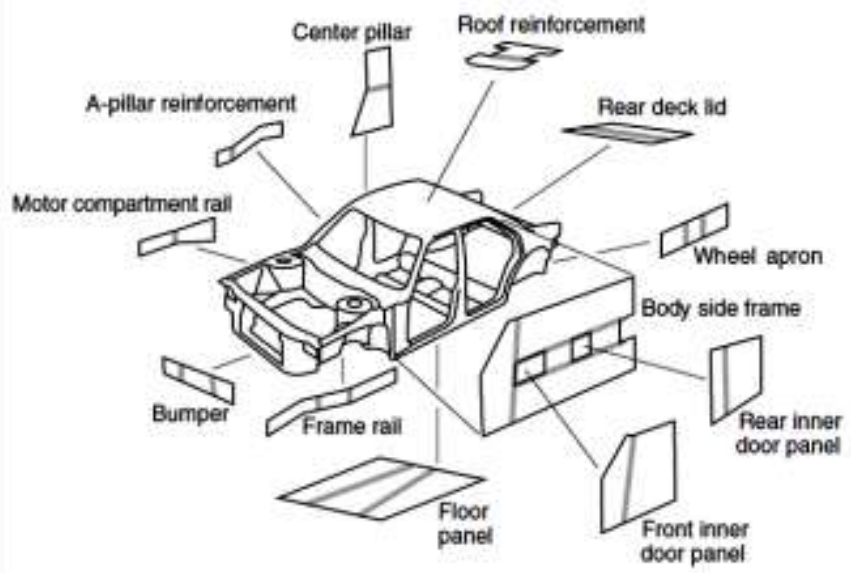

Figure 2. Exploded view of TWB body components [4].

By combining various material types, specifically different steels, into a single welded blank product and manufacturing engineers can "tailor" the best properties of different steels so that they are located precisely within the part where they are needed.

Different welding process have been used in the past for tailor welded blanks manufacturing, such as gas tungsten arc welding (GTAW) process, gas metal arc welding (GMAW) process or mash seam welding, currently, most of the tailor blanks are welded using the laser welding process, especially since high power lasers are commercially available [5].

This paper will investigate the resulted stresses and strains due to GMAW welding of a TWB joint using finite volume analysis. Large and small-sized geometries are constructed to evaluate the scaling effect on TWB welding.

\section{Progress of TWB technology}

The concept of tailor welded blanks (TWB) originated in the 1960s, but the first applications were introduced later, in the 1980s [1]. The use of laser welding to make up a single blank from different grades and thicknesses of galvanized 
sheet steel to form a blank for the floor pan of an Audi car model was developed by Thyssen Stahl AG in 1985. Although the use of TWBs at a mass production level was started in Europe, thereafter the use of this technology expanded rapidly all over the world [5].

\section{A. Materials for TWBs}

TWBs are commonly fabricated from combinations of high strength/lightweight materials with low cost deep drawing steels or aluminum alloys. Advanced high-strength steels (AHSS) like dual phase steels (DP Steels), transformation induced plasticity (TRIP) steels, multiphase (MP) steels, as well as, (6xxx, 7xxx) aluminum alloys represent examples of the commonly used materials. Regardless of the used welding method, complex structural changes on both the micro and the macro levels are expected in these materials. This makes the optimization of the welding and forming parameters very challenging.

For example, the weld area in steel TWBs becomes stronger than the base material due to microstructural changes. On the other hand, the weldment is typically weaker than the base material in aluminum TWBs. This affects the general deformation behavior of TWBs produced from these materials. In addition, the most effective welding method is material dependent. For example, due to the reflectivity of aluminum, laser welding is less effective than it is for steel TWBs [2].

In crash relevant components, the crash management is achieved through TWBs. The most cost efficient TWB solutions are those where both the material thickness and the grades are varied to avoid an additional reinforcement. For example, the central part of the B-pillar is made of thick plate with very high strength to provide a stiff part with limited deformations. The upper and lower part will be subjected to difficult forming processes. Hence, these parts are made of softer grades with higher formability [6].

\section{B. Fabrication Methods of TWBs}

TWBs are manufactured in three consecutive steps: blank cutting, welding and forming. Different manufacturing techniques can be employed in each of the main production steps as illustrated in Figure 3.

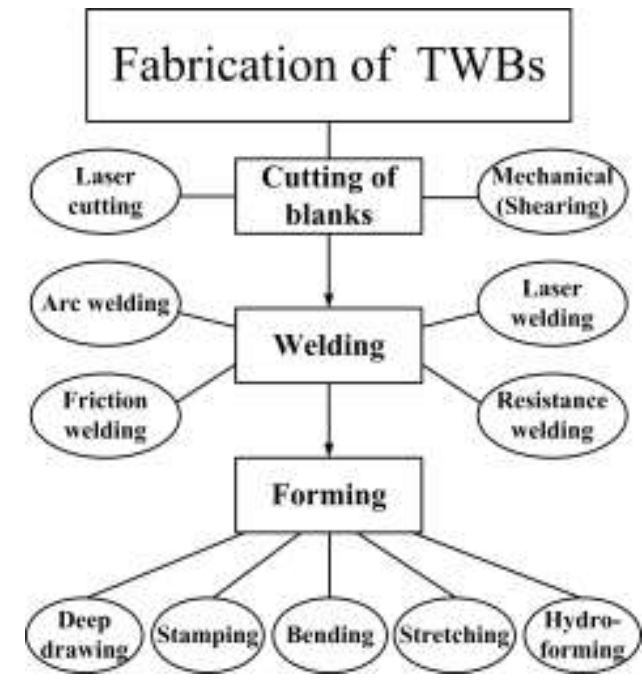

Figure 3. TWBs fabrication procedure and methods
It is well recognized that blank edge geometrical and microstructural features resulting from cutting can give very important influence to the subsequent operations, especially in sheet materials that possess high strength and relatively low formability.

A study on mechanical shearing of AHSS sheets was carried out by $\mathrm{Wu}$ and Hamed to characterize mechanically sheared edges. They developed a standard experimental procedure for characterizing the mechanically sheared edges used in TWBs [7]. Although, shear cutting is an easy and cheap cutting process, the resulting gap may be unacceptable for some subsequent welding operations, e.g. laser welding [8]. It is therefore beneficial to investigate the use of low cost welding methods, e.g. GMAW, as an alternative for the production of TWBs based on mechanically sheared blanks.

As shown in Figure 3, there are other welding methods that have been used in the production of TWBs. Friction stir welding (FSW) technique has been used for the production of TWBs made of aluminum alloys. In recent years, it has been extended to a wide range of metals and applications such as aluminum and steel TWBs welding [9].

Resistance mash seam welded joints are produced at lower temperatures compared to laser joints. Hence, they have better formability due to less martensite formation. However, the heat affected zone (HAZ) is nearly twice the width of the weld and some thickness increase at the joint is inevitable [10].

Today, the majority of TWBs are produced by laser cutting and laser welding from dissimilar materials or different thicknesses for structural optimization [9]. In spite of the relatively high cost of laser equipment, it's still more convenient for mass production in automotive industries.

GMAW welding method can operate at a low cost, but the amount of heat dissipated to the base metal is high. It is not only energy effective but the method compromises the material properties [9]. Kapustka et al. [11] studied GMAW for joining several AHSSs, including coated DP780, DP980, TRIP600, and TRIP780 of the thicknesses ranging from 1.34 to $1.54 \mathrm{~mm}$. Although the welding was for similar materials and thicknesses, the welding behaviors could be correlated to the TWB application.

In case of fusion processes, the original microstructure changes locally leading to a significant impact on three material properties that determine the formability of the blank in the subsequent forming stage: the yield strength, strain hardening, and failure strain. The reduced formability and/or the increased local residual stress affects both the production quality and the performance of the components based on TWB [1].

The formability and the behaviors of tailor welded blanks (TWBs) are affected in a synergetic manner by many interrelated factors. Important factors include base metal properties, thickness/strength ratio, weld process parameters and weld orientation [12].

Prediction of the TWB behavior during welding and forming can significantly reduce the lead time for the manufacturing of sheet metal components. The accuracy of the predictions depends greatly on the proper estimation of the properties of the weldment and the base metal and the changes that takes place during the manufacturing process. 
Proc. of the Third Intl. Conf. on Advances in Mechanical and Automation Engineering - MAE 2015.

Copyright $\odot$ Institute of Research Engineers and Doctors, USA .All rights reserved.

ISBN: 978-1-63248-080-4 doi: 10.15224/ 978-1-63248-080-4-33

\section{Simulation of TWBS}

Numerical simulation of TWBs represents a complicated multistage thermomechanical problem. The complexity is primarily due to the local change of mechanical properties caused by the welding process; in addition to the difficulties resulting from the weldment configuration when the welded blanks are not similar in thickness and/or material [13].

The forming behavior of TWBs can be simulated either by incorporating the properties of the weld zone or by assuming the weld region as a weld line without considering the properties of constituent base metals. Weld line movement is a common phenomenon during the drawing of TWBs and can lead to significant reduction in formability. Weld zone properties can be evaluated by tensile testing of subsize samples feeding into finite element simulation models for accurate forming behavior predictions [12].

\section{Model Description}

The gas metal arc welding (GMAW) process of blanks with different sizes and weldment configurations has been numerically simulated. Welding parameters have been extracted from the recommendations of the American Welding Society (AWS) for welding dissimilar materials.

\section{A. Blank size}

Two models of different blank sizes have been used to investigate the effect of blank size on the weldment quality. The large blank geometry consists of two 200x200 $\mathrm{mm}^{2}$ sheets, while the small-sized blanks are made of two 40x40 $\mathrm{mm}^{2}$ sheets (Figure 4).
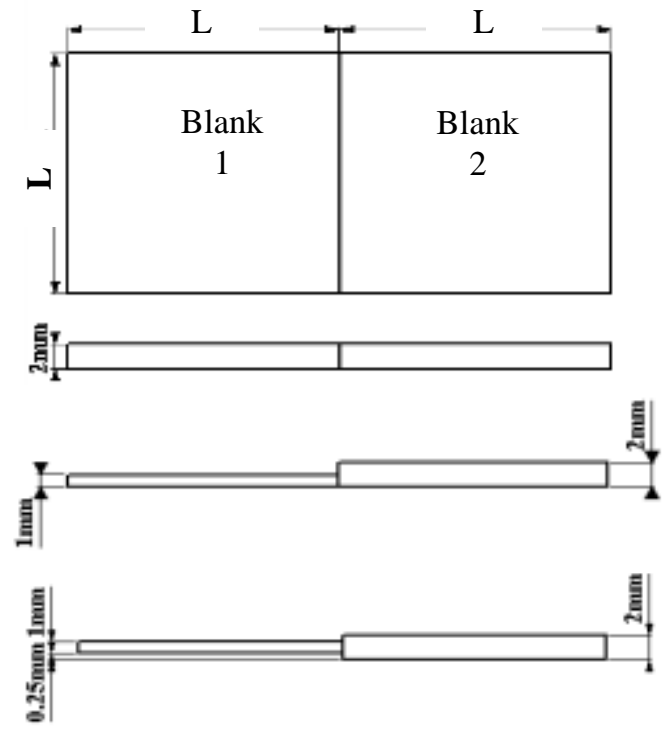

$\mathrm{L}=40 \mathrm{~mm}$ for small-sized blank, $\mathrm{L}=\mathbf{2 0 0} \mathbf{~ m m}$ for large-sized blank

Figure 4. Small and large-sized blank configurations

\section{B. Weldment configuration}

As shown in Figure 4, large and small-sized blanks have been combined from $200 \times 200 \mathrm{~mm}^{2}$ or $40 \times 40 \mathrm{~mm}^{2}$ sheets in three configurations: configuration 1 is a butt joint square edge, configuration 2 is a butt joint fillet weld, and configuration 3 is a butt joint double fillet weld. The same applies for small-sized blanks. The blanks were constructed from sheets of similar or different thicknesses and materials.
Sheets with thicknesses of 1 and $2 \mathrm{~mm}$ have been used in various combinations as given in TABLE I.

\section{Material models}

Low carbon steel A619 has been assigned to the blanks marked as blank 1 at both thicknesses of 1 and $2 \mathrm{~mm}$, while 304 austenitic stainless steels has been assigned to the $2 \mathrm{~mm}$ thick blanks marked as blank 2. Austenitic stainless steel (type 304) filler wire has been selected for the TWB welding.

Flow curves for type 304 stainless steel within the temperature range $20^{\circ} \mathrm{C}$ to $1500^{\circ} \mathrm{C}$ (Figure 5) as well as flow curves for $\mathrm{A} 619$ low carbon steel for temperatures ranging between $25^{\circ} \mathrm{C}$ and $1400^{\circ} \mathrm{C}$ (Figure 6) were extracted from MSC ${ }^{\circledR}$ Software databank. Other thermal properties of 304 stainless steel and A619 steel including melting point, specific heat capacity, thermal conductivity, and thermal expansion curves are retrieved from the materials databank provided by $\mathrm{MSC}^{\circledR}$ software.

TABLE I. BLANK COMBINATIONS AND MATERIAL ASSIGNMENT

\begin{tabular}{|c|c|c|}
\hline Blank & Blank 1 & Blank 2 \\
\hline $\begin{array}{c}\text { Thickness } \\
(\mathbf{m m})\end{array}$ & $\begin{array}{l}1 \mathrm{~mm} \\
2 \mathrm{~mm}\end{array}$ & $2 \mathrm{~mm}$ \\
\hline $\begin{array}{c}\text { Size } \\
(\mathbf{m m})\end{array}$ & $\begin{array}{c}200 \times 200 \\
40 \times 40\end{array}$ & $\begin{array}{c}200 \times 200 \\
40 \times 40\end{array}$ \\
\hline Material & A619 low carbon steel & 304 stainless steel \\
\hline
\end{tabular}

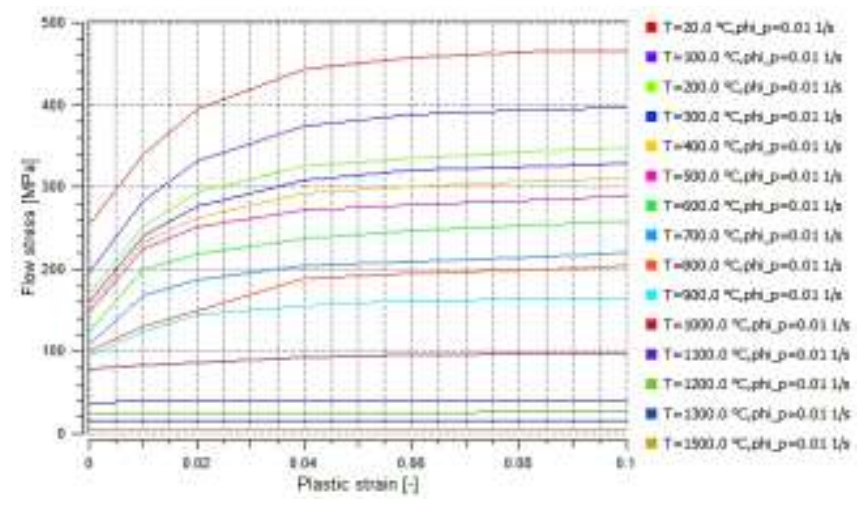

Figure 5. Flow curves of type 304 stainless steel

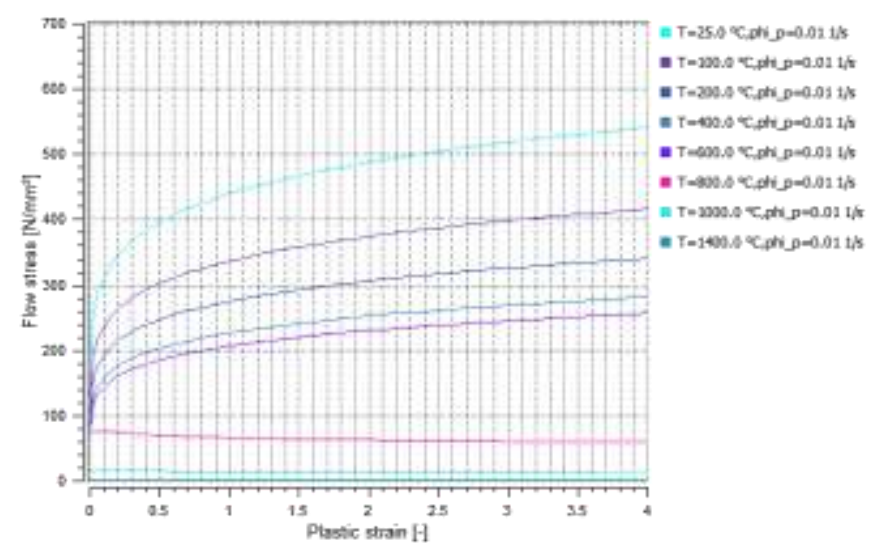

Figure 6. Flow curves of A619 low carbon steel 


\section{Welding parameters}

Welding parameters used in the simulation of GMAW welding of the selected material pair are listed in TABLE II. Parameters were developed to achieve adequate fusion without excessive penetration. A heat transfer efficiency of 0.75 was used. The heat source has been simulated with normally distributed double-ellipsoid volume source introduced by Goldak as shown in Figure 7 [14]. The geometrical parameters of the heat source were estimated using empirical relationships based on the weld throat size.

TABLE II. WELDING PARAMETERS USED IN GMAW OF TWBS

\begin{tabular}{|c|c|c|c|c|}
\hline $\begin{array}{c}\text { Current } \\
(\mathbf{A})\end{array}$ & $\begin{array}{c}\text { Voltage } \\
(\mathbf{V})\end{array}$ & $\begin{array}{c}\text { Travel Speed } \\
(\mathbf{m m} / \mathbf{S})\end{array}$ & $\begin{array}{c}\text { Heat Input } \\
(\mathbf{J} / \mathbf{c m})\end{array}$ & $\begin{array}{c}\text { Cooling time } \\
(\mathbf{s e c})\end{array}$ \\
\hline 100 & 18 & 10 & 1350 & 100 \\
\hline
\end{tabular}

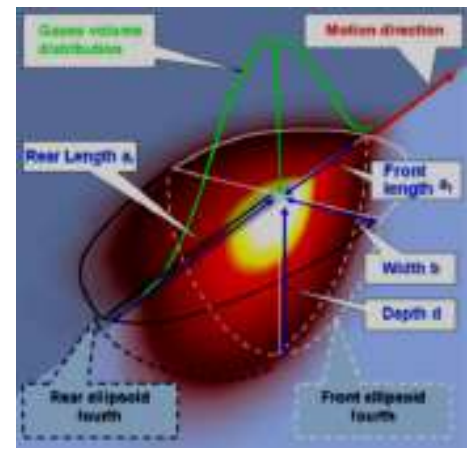

Depth $\mathrm{d}=1.54 \mathrm{~mm}$; Width $\mathrm{b}=1 \mathrm{~mm}$

Front length $\mathrm{a}_{\mathrm{f}}=1 \mathrm{~mm}$; Rear length $\mathrm{a}_{\mathrm{r}}=3 \mathrm{~mm}$

Figure 7. Heat source double-ellipsoid model by Goldak [14].

\section{Results and Discussion}

Examination of the results obtained from the large-sized blanks show that the stresses are primarily localized in the welding zones. The stresses induced in the stainless steel blanks, especially in heat affected zones and weld lines are much higher than those encountered in the carbon steel blanks in all of the three configurations (equal thickness butt weld, different thicknesses single fillet, different thicknesses double fillet). The distributions of effective stress magnitudes in the large-sized configurations are shown in Figure 7. The stress distribution in case of double fillet shows relatively gradual stress gradient away from the weld line. However a wider stressed zone was calculated.

In the small-sized blanks, the stresses above $100 \mathrm{MPa}$ are distributed over $40 \%$ of the entire blank area (nearly 30 $\mathrm{mm}$ ) and are not just localized in the welding zones. The effective stress distribution in the different configurations is shown in Figure 8. It should be noticed that the largest stressed zone was calculated in case of butt welding of blanks with the same thicknesses. The highest stress levels are predicted in the stainless steel blank. This is valid for both blank sizes. The calculated stress levels after welding and cooling are relatively high for the selected materials. The 304 stainless steel has ultimate tensile strength of 470 MPa at room temperature while A619 deep drawing steel have which have ultimate strength of $550 \mathrm{MPa}$ (review Figures 5 and Figure 6). The high levels of induced residual stresses are expected to highly affect the subsequent forming process(s).

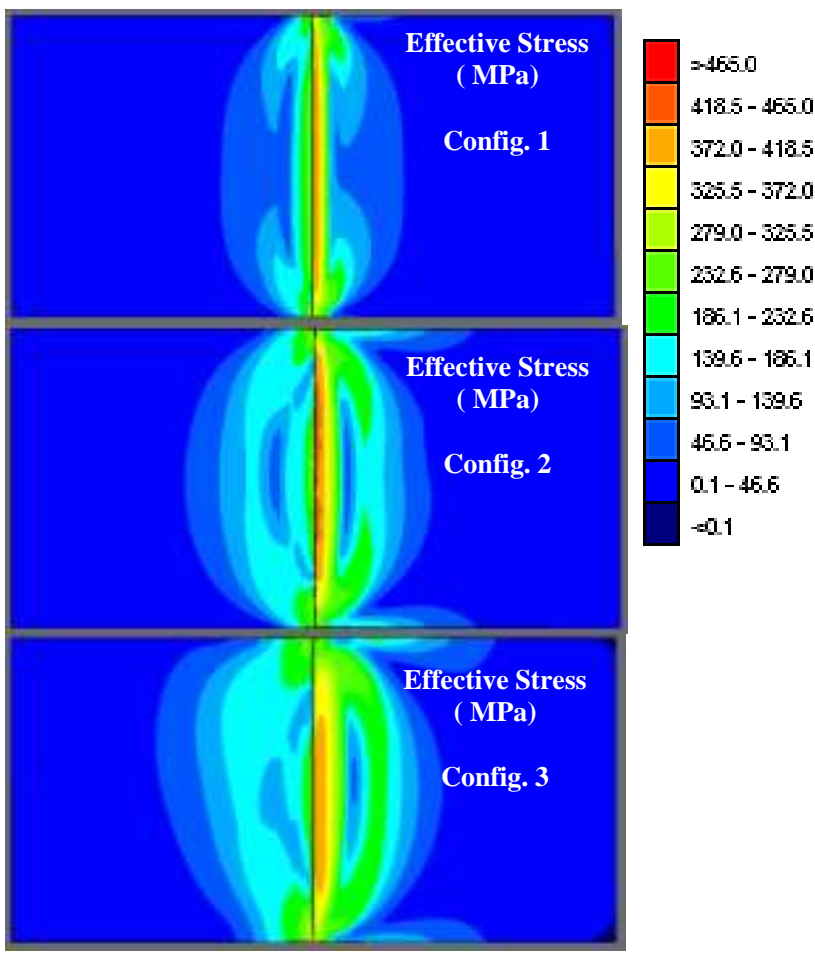

Figure 8. Effective stress in large-sized blanks after 100 seconds of cooling

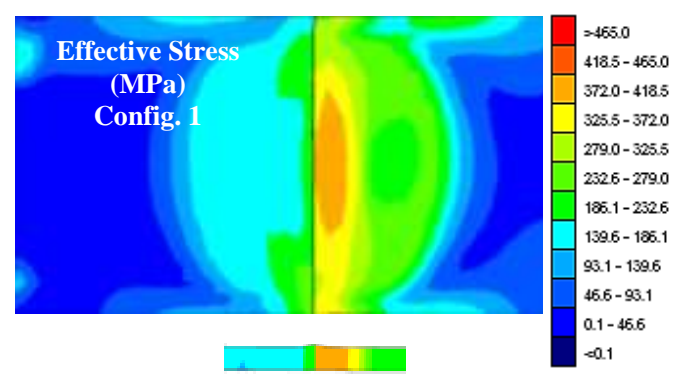

(a)

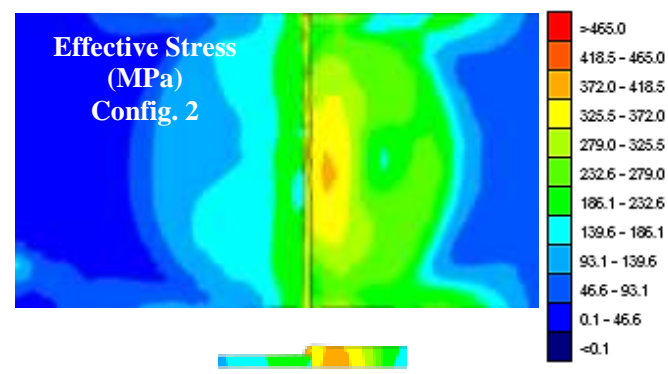

(b)

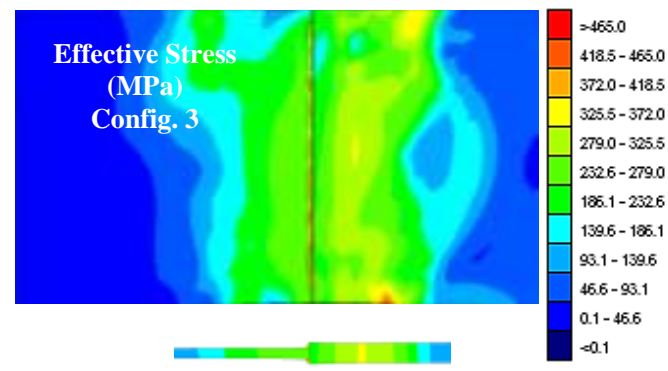

(c)

Figure 9. Effective stress distribution in the small-sized blanks Upper: plan view; Lower: zoomed mid-section elevation 
Proc. of the Third Intl. Conf. on Advances in Mechanical and Automation Engineering - MAE 2015.

Copyright $(\odot$ Institute of Research Engineers and Doctors, USA .All rights reserved.

ISBN: 978-1-63248-080-4 doi: 10.15224/ 978-1-63248-080-4-33

Comparison of the in plane XY-shear stress in case of large-sized blanks (Figure 10) and small-sized blanks (Figure 11) shows that the shear stresses developed in case of small-sized blanks are 70 to $100 \mathrm{MPa}$ higher in magnitude than those in the large-sized blanks. In addition, the maximum shear zones lie mainly on $\pm 45^{\circ}$ to the weld line extending from the weld start/end point. However, the spread of the stressed zone is larger in the smaller blanks $(\sim 50 \%$ of blank area) than in the larger ones $(\sim 30 \%)$. Moreover, no favorable orientation can be predicted in the small-sized blanks.

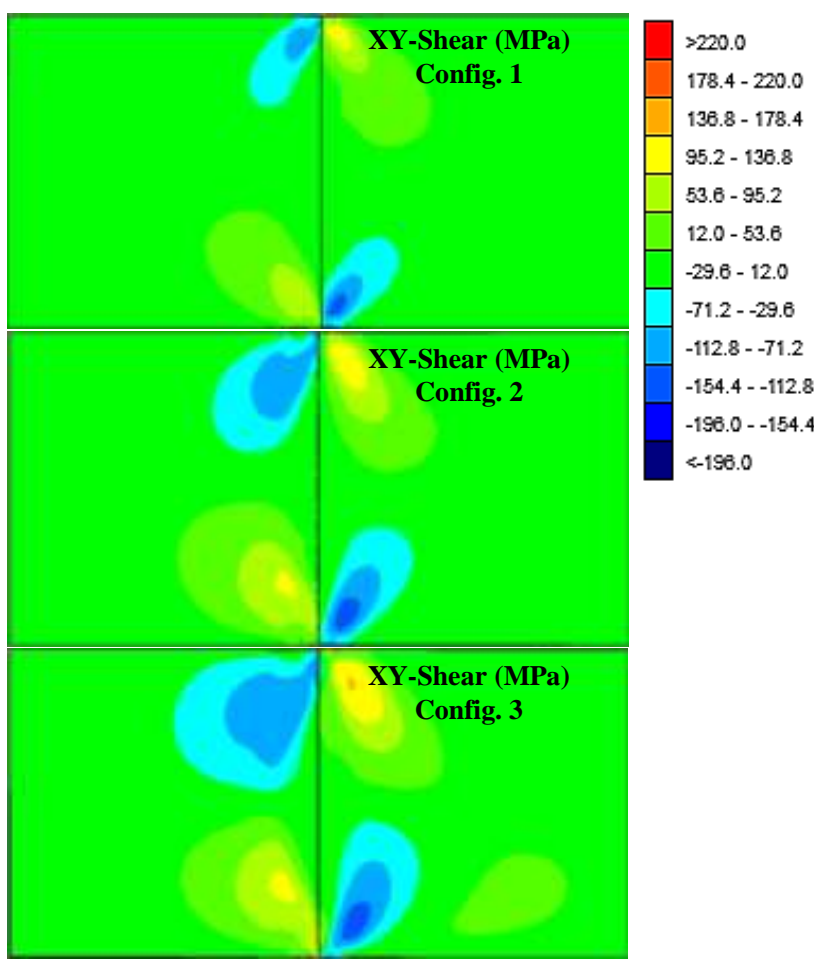

Figure 10. In-plane shear stress distribution in large-sized blanks

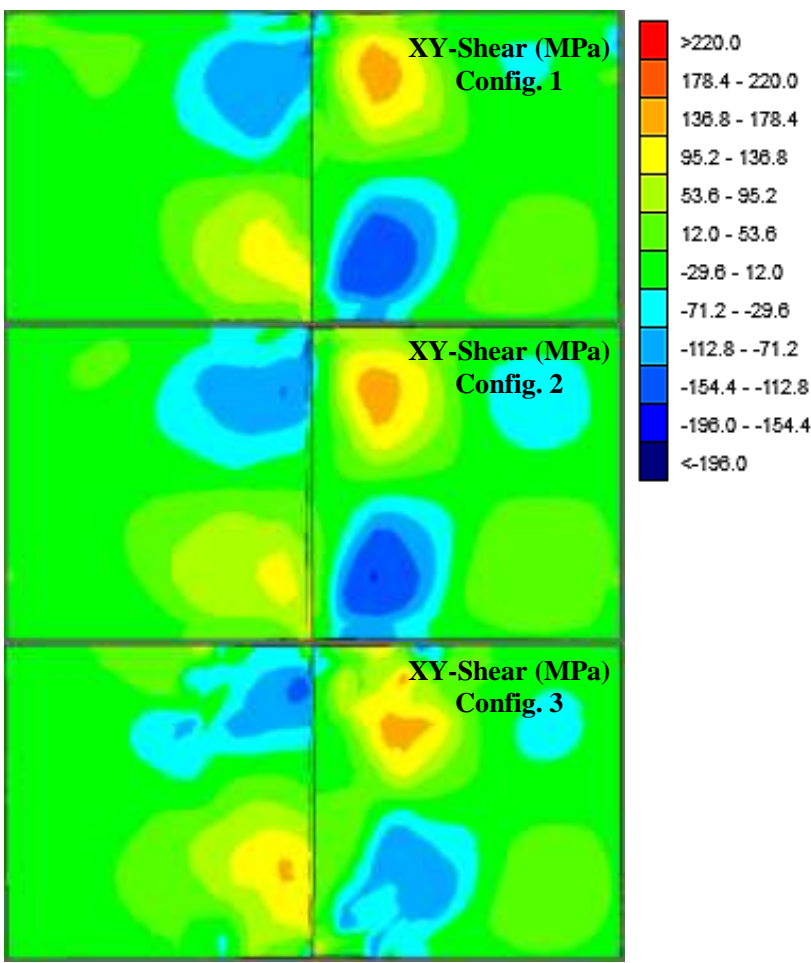

Figure 11. In-plane shear stress distribution in small-sized blanks
The high stressed portion in the smaller blanks increases the probability of failure and warping in following forming operation (e.g. deep drawing). The effect of anisotropy on the forming result should be considered during the simulation of successive forming processes.

Maximum values for effective plastic strain, the maximum shear stress and out of plane Z-distortion have been calculated for both small and large-sized blanks as shown in TABLE III. Maximum out of plane distortion for large-sized blanks reaches $4 \mathrm{~mm}$ in this case (Figure 12).

Although, the maximum plastic strain values are comparable in case of configuration 1 and 2, the maximum out of plane distortion is larger in case of large-sized blank due to the blank dimension. An example of effective plastic strain in small-sized blanks is represented in Figure 13.

It can be noticed that the maximum distortion takes place in the thinner and weaker blank (up to the maximum induced plastic strain) near the weld zone, while the maximum residual stress develop in the thicker and stronger blank. Large stresses in the thinner and/or weaker material may lead to sheet thinning and increase in failure probability, especially when these zones are subjected to excessive plastic strain in subsequent forming stage(s).

The level of stresses that develop after cooling depends on the type of material, the cooling rate, the clamping used for the fixation of the blanks. The development of the stresses during the cooling process is shown in Figure 14.

TABLE III. RESULTS OF FinITE VOLUME ANALYSIS

\begin{tabular}{|c|c|c|c|c|}
\hline \multicolumn{5}{|c|}{ Large size blanks } \\
$\begin{array}{c}\text { Weldment } \\
\text { configuration }\end{array}$ & $\begin{array}{c}\text { Max. effective } \\
\text { stress range } \\
\text { (MPa) }\end{array}$ & $\begin{array}{c}\text { Max. effective } \\
\text { plastic strain } \\
\text { range }\end{array}$ & $\begin{array}{c}\text { Max. XY } \\
\text { Shear stress } \\
\text { (MPa) }\end{array}$ & $\begin{array}{c}\text { Max. Z } \\
\text { distortion range } \\
\text { (mm) }\end{array}$ \\
\hline $\mathbf{1}$ & $407-453$ & $0.11-0.12$ & $117-144.4$ & $0.25-0.28$ \\
\hline $\mathbf{2}$ & $415-461$ & $0.25-0.28$ & $101-133$ & $0.63-0.70$ \\
\hline $\mathbf{3}$ & $417-464$ & $0.69-0.76$ & $177-218$ & $3.31-4.70$ \\
\hline $\mathbf{5}$ \\
\hline $\mathbf{1}$ & $365-405$ & $0.09-0.10$ & $121-152$ & $0.27-0.30$ \\
\hline $\mathbf{2}$ & $419-466$ & $0.27-0.30$ & $119-152$ & $0.19-0.22$ \\
\hline $\mathbf{3}$ & $419-466$ & $0.14-0.15$ & $152-190$ & $0.11-0.14$ \\
\hline
\end{tabular}

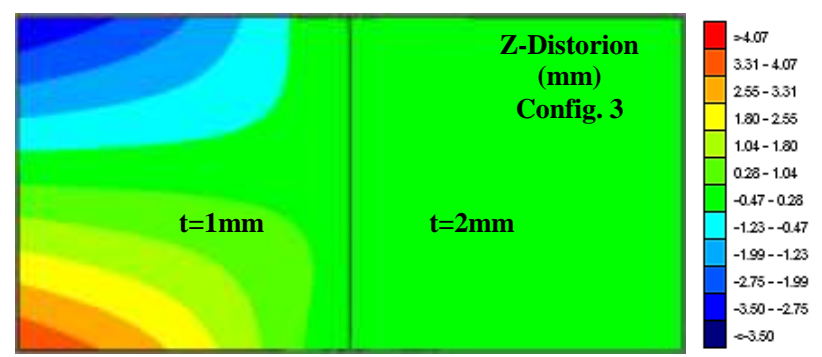

Figure 12. Z-distortion in the large-sized blanks with double fillet welds

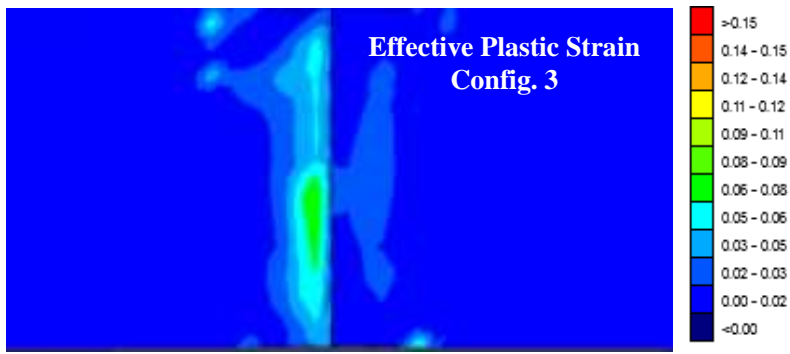

Figure 13. Effective plastic strain distribution in the small-sized blanks 


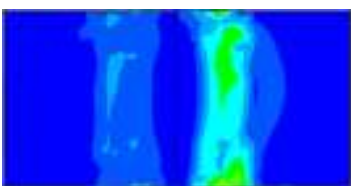

$t_{\text {cool }}=0 \mathrm{sec}$.

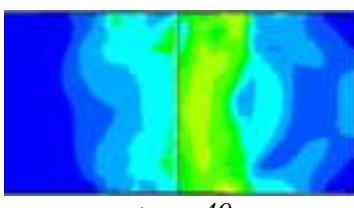

$t_{\text {cool }}=40 \mathrm{sec}$ $t_{\text {cool }}=20 \mathrm{sec}$.

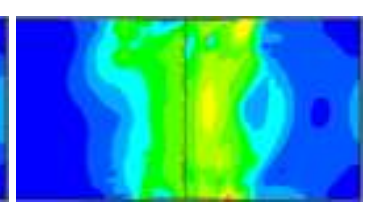

$t_{\text {cool }}=100 \mathrm{sec}$.
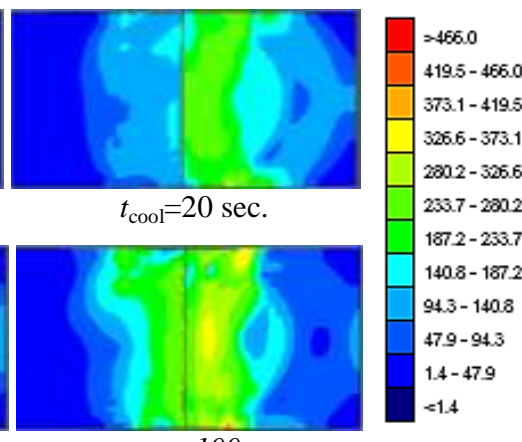

Figure 14. Development of stresses upon cooling of small-sized blanks

\section{v. Conclusion}

The goal of this paper was to study the induced stresses in tailor welded blanks due to GMAW welding process. Analysis using finite volume method was implemented in similar models with two different blank sizes to investigate the scaling effect. Welding of the blanks was simulated with three different configurations of each size. Heat input per unit length has been kept constant during simulations. Although the maximum range for effective stresses are comparable in all cases, the distribution of stresses and strains are completely different. Hence, the distortions induced in the large-sized blanks are higher than those in the small-sized blanks. However, the portion of area which is influenced by the residual and shear stresses in the smallsized blanks are larger than stressed zones in larger-sized blanks. Subsequent forming and stamping operations will be affected especially for the small-sized blanks. The study of cooling effects on the developed residual stresses and distortion is also very important before considering subsequent forming of TWBs.

\section{Outlook}

Simulation of stamping and deep drawing operations using welded blanks taking the developed residual stresses into consideration should be performed. In addition, the formability, spring back and thinning should be investigated and the results should be validated experimentally.

\section{Acknowledgment}

The authors would like to thank the Science and Technology Development Fund (STDF), Egypt, for the financial support of this research project (Grant \#12704/2015).

The cooperation of the Institute of Metal Forming and Metal Forming Machines, Leibniz Universitaet Hannover, within the framework of this project is highly appreciated.

\section{References}

[1] A. A. Zadpoor and J. Sinke, "Weld metal ductility and its influence on formability of tailor welded blanks," in Failure Mechanisms of Advanced Welding Processes, X. Sun, Ed., Cambridge, Woodhead Publishing Limited, 2010, pp. 258- 288.

[2] B. L. Kinsey, "Tailor welded blanks for the automotive industry," in Tailor welded blanks for advanced manufacturing, B. L. Kinsey and X. Wu, Eds., Cambridge, Woodhead Publishing Limited, 2011, pp. 164-180.

[3] S. Semiatin, Ed., "Forming of Steel Tailor-Welded Blanks," in ASM Handbook, Volume 14B, Metalworking: Sheet Forming, 2006, pp. 539-546.
[4] E. Kannatey and A. Jr., "Principles of Laser Materials Processing", New Jersey: John Wiley \& Sons, Inc., 2009, pp. 547-556.

[5] E. V. Couso and J. V. Gómez, "Laser Beam Welding and Automotive," in Advanced Structured Materials series: Structural Connections for Lightweight Metallic Structures, vol. 8, P. M. G. P. Moreira, L. F. M. da Silva and P. M. S. T. de Castro, Eds., Springer, 2012, pp. 75-78.

[6] http://automotive.arcelormittal.com/flipflop/fce/Tailored_Blanks/Cata logue-Chapter1/index.html," Arcelormittal. [Online]

[7] X. Wu and B. Hamed, "Characterization of Mechanically Sheared Edges of Dual Phase Steels," Department of Mechanical Engineering, Wayne State University, Detroit, 2009.

[8] B. C. and F. O. Olsen, "Pulsed Mode Laser Cutting of Sheets for Tailored Blanks," Journal of Materials Processing Technology, vol. 115, pp. 131-135, 2001.

[9] X. Wu, "Advanced high-strength steel tailor welded blanks (AHSSTWBs)," in Tailor welded blanks for advanced manufacturing, B. L. Kinsey and X. Wu, Eds., Cambridge, Woodhead Publishing Limited, 2011, pp. 118-163.

[10] R. Padmanabhan, M. Oliveira and L. F. Menezes, "Lightweight metal alloy tailor welded blanks," in Tailor welded blanks for advanced manufacturing, B. L. Kinsey and X. Wu, Eds., Cambridge, Woodhead Publishing Limited, 2011, pp. 97-117.

[11] N. Kapustka, C. Conrardy, S. Babu and C. Albright, "Effect of GMAW Process and Material Conditions on DP 780 and TRIP 780 Welds," WELDING JOURNAL, 2008.

[12] K. Narasimhan and R. G. Narayanan, "Deformation of tailor welded blanks during forming," in Tailor welded blanks for advanced manufacturing, B. L. Kinsey and X. Wu, Eds., Cambridge, Woodhead Publishing Limited, 2011, pp. 24-47.

[13] A. A. Zadpoor, J. Sinke and R. Benedictus, "Numerical simulation modeling of tailor welded blank forming," in Tailor welded blanks for advanced manufacturing, B. L. Kinsey and X. Wu, Eds., Cambridge, Woodhead Publishing Limited, 2011, pp. 68-94.

[14] J. A. Goldak, M. Akhlaghi, "Computational Welding Mechanics", Sringer, 2005, pp. 16-64.

About Author (s):

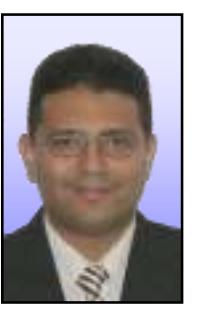

Dr.-Ing. Islam El-Galy, earned his doctorate from IFUM, Leibniz University of Hannover, 2011. Currently, he fills the position of Assistant Professor at the Faculty of Engineering, Alexandria University. Research interests include advanced materials and forming technologies in addition to monitoring of manufacturing processes using acoustic-, thermaland optical-based techniques.

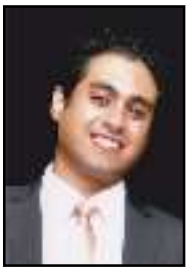

Eng. Ahmed El-Masry has obtained his BSc degree from the Production Engineering Dept., Alexandria University, 2012. Currently, he is working as a research and teaching assistant at the Faculty of Engineering, Alexandria.

Research interests include material characterization and stress analysis of welding and forming processes.

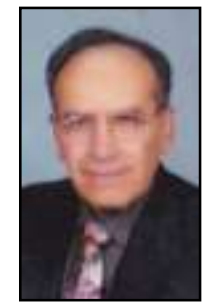

Prof. Dr. Ali El-Ashram is currently Emeritus Professor and former Head of Production Engineering Dept., Alexandria University.

With nearly 50 years of academic and professional experience, Prof. El-Ashram is one of the top ranked Egyptian scientists and experts in the fields of design, material characterization and failure analysis especially in oil and gas industries. 